\title{
Flexural Behavior of Polypropylene Fiber Reinforced Concrete Beams
}

\author{
K.Ramakrishnan, S. Aravind, C. Kumar
}

\begin{abstract}
This paper portrays an experimental research conducted to determine the strength and flexural behavior of the polypropylene fiber reinforced beams. Polypropylene fibers were being added in concrete with different dosages viz., 0.6, 0.8, 1.0, $1.2,1.4$, and $1.6 \%$ to the total volume of concrete and Ordinary Portland Cement (OPC) and Portland Slag Cements (PSC) were added in the ratio of 60:40 with the overall cement content. Cubes were cast for compressive strength test and cylinder were cast for tensile strength test and beams were cast for flexural strength test. Seven beams were tested; one normal beam without polypropylene fiber and six beams with polypropylene fiber were cast and flexural strength test was conducted. Polypropylene fiber and slag cements were used in mass concrete structures to reduce heat of hydration and shrinkage cracks. Flexural strength and the cracking pattern were monitored during the test. The results indicated that the addition of polypropylene fibers and slag cements in concrete significantly increased the compressive strength, tensile strength, flexural strength and load carrying capacity of beams with different cracking patterns.
\end{abstract}

Keywords : Polypropylene fiber, flexural strength, Portland slag cement, tensile, compressive, beams.

\section{INTRODUCTION}

Polypropylene becomes an attractive material for several applications including buildings, industrial structures, nuclear plants, road pavements etc., Polypropylene fiber acts as secondary reinforcement to the concrete which controls shrinkage cracking and increases the impact resistance and toughness. Primary role of polypropylene fibers is to modify the fresh concrete, the presence of polypropylene fiber increases the homogeneity of concrete, stabilizing the movement of solid particles and blocking the bleed water channels, Polypropylene fibers reduce the bleed capacity of the concrete and help to reduce plastic shrinkage. It has been recognized that polypropylene fiber reinforcement concrete is an effective way to enhancing strength criteria. The blending of slag cement with portland cement helps to produce consistent concrete mixture with higher strength, low permeability and less prone to chemical attack and rebar corrosion. The hydration of Portland Cement leads to the formation of Calcium Silicate Hydrate (CSH) and calcium hydroxide $\left(\mathrm{Ca}\left(\mathrm{OH}_{2}\right)\right.$. $\mathrm{CSH}$ acts as a glue that imparts strength

Revised Manuscript Received on December 05, 2019.

* Correspondence Author

Dr. K. Ramakrishnan*, School of Civil Engineering, SASTRA Deemed to be University, Thanjavur, India. Email: ramakrishnan@civil.sastra.edu

S. Aravind, School of Civil Engineering, SASTRA Deemed to be University, Thanjavur, India.. Email: aravinds@sastra.ac.in

C. Kumar, Former M.Tech. student School of Civil Engineering , SASTRA Deemed to be University, Thanjavur, India. Email: kumarcheeramy@gmail.com to concrete and also helps in binding concrete together while $\mathrm{Ca}(\mathrm{OH})_{2}$ is a byproduct of the cement hydration process and it does not influence strength. The slag cement reacts with water and $\mathrm{Ca}(\mathrm{OH})_{2}$ to form more $\mathrm{CSH}$ thus densifying the concrete matrix. This denser cement paste in slag cement concrete reduces pore size and lower concrete permeability. Slag cements in concrete gives better finishing, low permeability, and workability. In the environmental aspects it reduces greenhouse gases emissions. The use of slag cement impacts the concrete flexural strength substantially. Load deflection measurement, failure and cracking behavior, and flexural capacity of beams are presented and discussed in this paper.

Angel M. Lopez-Beundia et. al. (2013) studied that the Surface treatments on a polypropylene (PP) fibre have contributed to the improvement of fibre/concrete adhesion in fibre-reinforced concrete. Treatment modified the surface chemistry and topography of the fibre by introducing sodium moieties and created additional fibre surface roughness. Modifications in the fibre surface led to an increase in the adhesion properties between the treated fibres and concrete and an improvement in the mechanical properties of the fibre-reinforced concrete composite as compared to the concrete containing untreated PP fiber. Elser M et. al. (1996) studied the fracture process in front of and behind the crack tip of fiber reinforced concrete under biaxial loading. Héctor Cifuentes et. al. (2013) studied the influence of the properties of polypropylene fibers on the fracture behavior of FRC and observed that the ductility of the concrete is dependent on the fiber that is used in the concrete. A. Nobili et. al. (2013) studied the use of Polypropylene fibers in road pavement and concluded that FRC provides efficient, safe as well as cost effective design solution for roadways and tunnels. A.A Ramezanianpour (2013) et. al. studied the effect of PPF on concrete properties and observed that the PPF addition leads to initial increase of split tensile and flexural strength of concrete although the strength decreases at later ages of concrete. The addition of the fibers reduces the permeability and capillary porosity by pore blocking effect and hence enhances the durability of the concrete. Sydney Furlan Jr et al. (1997) studied the shear behavior of FRC beams and concluded that the addition of fibers in concrete leads to increased shear strength, stiffness and ductility. Machine Hsie et. al. (2008) studied the mechanical properties of PPF -FRC concrete and concluded that the hybrid fibers can mix well with concrete and can reduce the drying shrinkage strain. Jianping Zhu et. al. (2012) studied the effect of particle size of slag particles on the properties of portland cement and he observed that the fineness of the slag particles plays an important role in the hydration of cement and slag particles with proper particle size distribution

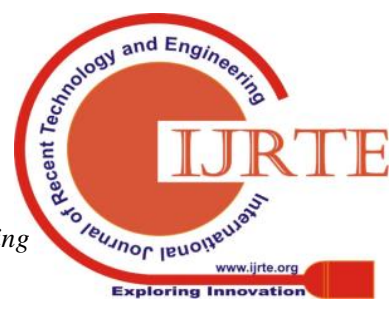


has better properties than that of the reference concrete. Gonzalo Martinez-Barrera et. al. (2011) studied the mechanical properties of PPF - FRC after being exposed to gamma irradiation and he found the the exposure to gamma radiation has improved the mechanical properties of the concrete. M. Elser et. al. (1996) studied the fracture behavior of PPF - FRC concrete under uniaxial and biaxial loading and estimated the amount of fibers necessary for achieving desirable properties of concrete by modeling based on the amount of fracture energy absorbed by the fibers.

\section{EXPERIMENTAL INVESTIGATION}

An experimental investigation was carried out to produce high strength concrete with the addition of polypropylene fibers with minimum percentages and slag cements to the concrete. It comprises of casting of cubes for compressive strength, casting of cylinder for split tensile strength, and casting of beams for flexural test under two point loading test. The materials used, mix proportions and the test methods are described in the following sections.

\section{A. Materials used}

1) Cement -53 grade OPC conforming to IS: 12269 and 33 grade PSC conforming to IS: 455 was used. The relative density of OPC and PSC was found to be 3.15 and 3.06 respectively by proper experimentation.

2) Fine aggregate-River sand passing through $4.75 \mathrm{~mm}$ sieve and available locally was used. The relative density was found to be 2.65 .

3) Coarse aggregate- Coarse aggregates which are retained in $4.75 \mathrm{~mm}$ sieve were used. The specific gravity was found to be 2.75 .

4) Fiber- Polypropylene fibers of micro filament type having a diameter of $0.2 \mathrm{~mm}$ and length of $12 \mathrm{~mm}$ with aspect ratio of 60 was used as per ASTM-C1116 standards.

5) Water - Fresh water available in the local sources was used for the mixing and curing of polypropylene beams.

6) Super Plasticizer- To accelerate the workability of polypropylene fiber concrete, CONPLAST-SP430 ES2, high performance plasticizer has been used as per ASTM-C-494.

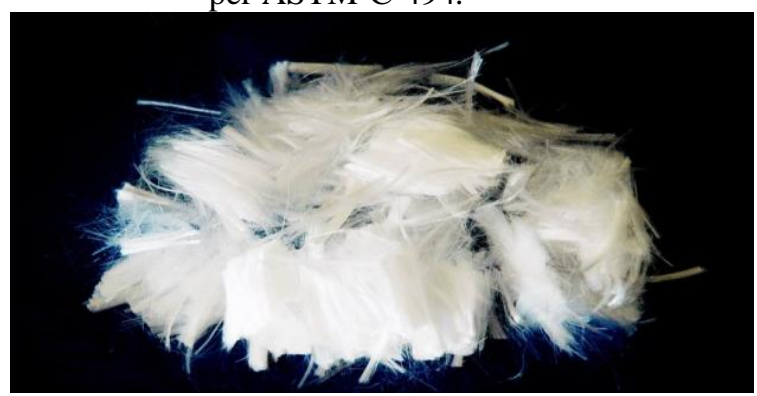

Fig. 1 View of polypropylene fiber

\section{B. Casting}

A concrete mixture with a ratio of 1: 1.772: 3.004 , where the OPC and PSC cement were adopted in the ratio of 60:40 as per the optimum content is prepared. Cubes, cylinders and beams were casted with varying fiber content of $0.6,0.8,1.0$, $1.2,1.4,1.6 \%$ were cast and was allowed to be in the mould for a day. Demoulding was done after a day and the specimens were then cured for 7, 14 and 28 days respectively. 14 day testing of specimens is not mandatory. It was learnt that about $90 \%$ of the strength of concrete is attained at that age and hence the test proves to be a good reference point with which the quality of concrete can be ascertained at an earlier age. Super plasticizer was also added.

\section{Testing}

1) Compressive strength test- A compressive strength test determines behavior of material under crushing loads. The specimen is compressed and deformation at various loads is recorded. $100 \mathrm{~mm} \mathrm{x}$ $100 \mathrm{~mm} \times 100 \mathrm{~mm}$ size cubes were cast and all the cubes were tested under compression in computerized compression testing machine of 3000 $\mathrm{kN}$ capacity. The specimen was compressed and deformation at various loads were recorded.

2) Split tensile test - To determine the tensile strength of concrete it is necessary to determine the load at which the concrete members may crack under split tensile force. The split tensile strength on cylinder was tested in a computerized compressive testing machine of capacity $3000 \mathrm{kN}$ capacity. $100 \mathrm{~mm} \mathrm{x}$ $200 \mathrm{~mm}$ cylinders were cast and tested for determining the tensile strength.

3) Flexural strength test - The test was conducted with Universal Testing Machine with the test set up as shown in Figure 2. The span of the beam between the supports is $1000 \mathrm{~mm}$, thus the flexure span was the middle span of length $333.3 \mathrm{~mm}$. The test was continued until the ultimate load was reached and the crack patterns were drawn. The size of the beam adopted for testing was $100 \mathrm{~mm}$ x150 mm x 1200 $\mathrm{mm}$.

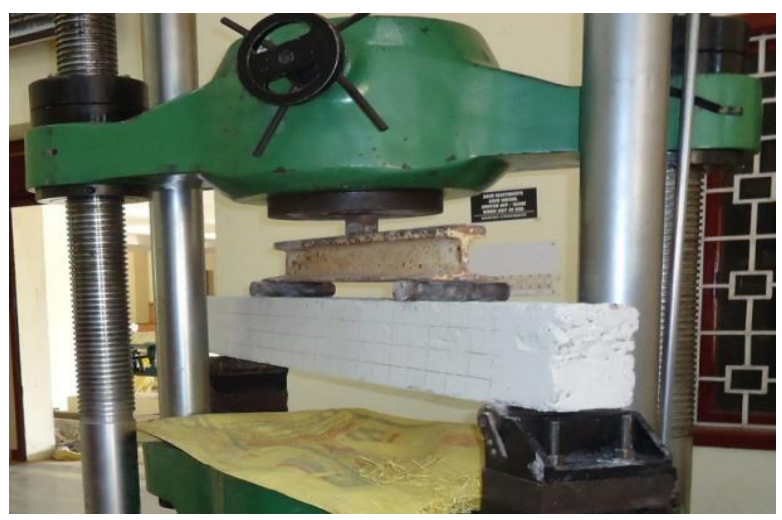

Fig. 2 Test setup of two point loading

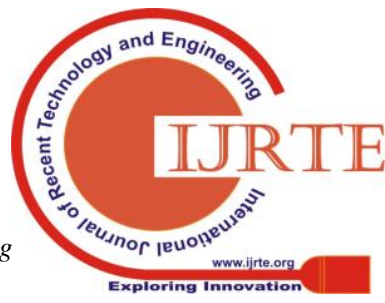




\section{RESULTS AND DISCUSSIONS}

\section{A. Compressive strength}

The compressive strength results of cubes were presented in table 1 .

TABLE I. COMPRESSIVE STRENGTH OF CUBES

\begin{tabular}{|l|l|c|c|c|}
\hline \multirow{2}{*}{ S.No. } & \multicolumn{1}{|c|}{ Specimen } & \multicolumn{3}{c|}{ Compressive strength } \\
\cline { 3 - 5 } & & $\mathbf{7}$ & $\mathbf{1 4}$ & $\mathbf{2 8}$ \\
Days & & \multicolumn{1}{c|}{ Days } & Days \\
\hline 1 & Controlled & 20.26 & 30.65 & 40.52 \\
\hline 2 & PPFRC 0.6\% & 28.25 & 32.80 & 40.75 \\
\hline 3 & PPFRC 0.8\% & 30.10 & 34.8 & 43.25 \\
\hline 4 & PPFRC 1.0\% & 30.95 & 36.25 & 44.05 \\
\hline 5 & PPFRC 1.2\% & 32.89 & 38.48 & 46.85 \\
\hline 6 & PPFRC 1.4\% & 34.09 & 37.96 & 48.75 \\
\hline 7 & PPFRC 1.6\% & 31.05 & 42.00 & 47.70 \\
\hline
\end{tabular}

\section{B. Split tensile strength}

The tensile strength results of cylinder were presented in table 2 .

TABLE II. TENSILE STRENGTH OF CYLINDERS

\begin{tabular}{|l|l|l|l|l|}
\hline \multirow{2}{*}{ S.No. } & \multicolumn{2}{|c|}{ Specimen } & \multicolumn{3}{c|}{ Tensile strength (MPa) } \\
\cline { 3 - 5 } & & $\begin{array}{c}7 \\
\text { Days }\end{array}$ & $\begin{array}{c}\mathbf{1 4} \\
\text { Days }\end{array}$ & $\begin{array}{c}\mathbf{2 8} \\
\text { Days }\end{array}$ \\
\hline 1 & Controlled & 2.70 & 3.04 & 3.40 \\
\hline 2 & PPFRC 0.6\% & 2.80 & 3.16 & 4.20 \\
\hline 3 & PPFRC 0.8\% & 2.86 & 3.32 & 4.27 \\
\hline 4 & PPFRC 1.0\% & 3.02 & 3.43 & 4.47 \\
\hline 5 & PPFRC 1.2\% & 3.12 & 3.52 & 4.60 \\
\hline 6 & PPFRC 1.4\% & 3.18 & 3.82 & 4.91 \\
\hline 7 & PPFRC 1.6\% & 3.51 & 3.75 & 4.87 \\
\hline
\end{tabular}

\section{Flexural strength}

The flexural strength results of beams were presented in table 3 .

\section{TABLE III. FLEXURAL STRENGTH OF BEAMS}

\begin{tabular}{|l|l|l|}
\hline \multicolumn{1}{|c|}{ Specimen } & \multicolumn{1}{|c|}{ Maximum load $(\mathbf{k N})$} & \multicolumn{1}{|c|}{$\begin{array}{c}\text { Flexural strength } \\
\left(\mathbf{N} / \mathbf{m m}^{2}\right)\end{array}$} \\
\hline Controlled & 36.85 & 4.094 \\
\hline PPFRC 0.6\% & 43.25 & 4.806 \\
\hline PPFRC 0.8\% & 44.8 & 4.978 \\
\hline PPFRC 1.0\% & 48.1 & 5.344 \\
\hline PPFRC 1.2\% & 50.25 & 5.583 \\
\hline PPFRC 1.4\% & 53.85 & 5.983 \\
\hline PPFRC 1.6\% & 57.85 & 6.428 \\
\hline
\end{tabular}

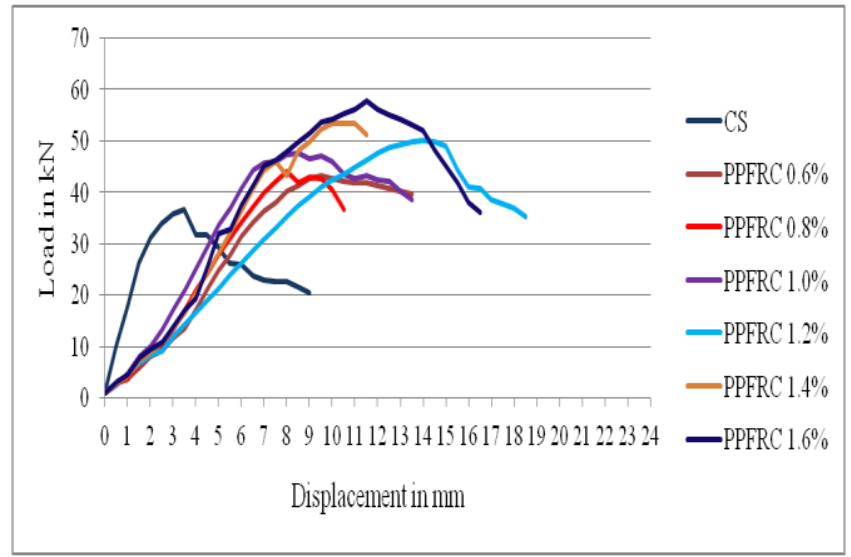

Fig. 4 Load - displacement curve

\section{Discussion}

1) The addition of polypropylene fibers increased the compressive strength and split tensile strength of the concrete at all ages compared to a control mix. There is also a significant gain in strength with age upto 28 days.

2) The addition of slag to OPC resulted in the increased compressive and flexural strength. This is because of the confinement of pores in the concrete system by slag particles.

3) Further tests can be conducted to determine the optimum content of polypropylene fiber and slag in the concrete system

\section{CONCLUSION}

The following conclusions were obtained based on the results of the compressive strength of cubes, tensile strength of cylinders and the flexural behavior of beams.

1) The addition of polypropylene fibers increased the compressive strength and split tensile strength of the concrete at all ages compared to a control mix. There is also a significant gain in strength with age upto 28 days.

2) A higher value of 28 day compressive strength as 47.7 $\mathrm{MPa}$, tensile strength as $4.87 \mathrm{MPa}$ and flexural

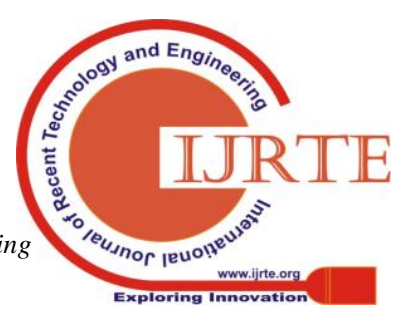


strength as $6.428 \mathrm{~N} / \mathrm{mm}^{2}$ was obtained at $1.6 \%$ of polypropylene fiber content in concrete.

3) It was observed that the cracking pattern were reduced when compared with the controlled mix.

4) The compressive and flexural strength of slag cement were observed to be more than that of OPC.

5) The failure mode of the beam was in both flexure and shear. Flexural cracks developed first followed by shear crack.

\section{REFERENCE}

1. Angel M. López-Buendía, María Dolores Romero-Sánchez, Verónica Climent, Celia Guillemb, "Surface treated polypropylene fibres for reinforced concrete", Cement and Concrete Research, vol. 54, pp. 029-035, 2013.

2. M. Elser, E.K. Tschegg, S.E. Stanzl Tschegg, "Fracture behavior of polypropylene-fibre reinforced concrete under biaxial loading: an experimental investigation", Composites science and technology, vol. 56, pp. 933-945, 1996.

3. Héctor Cifuentes, Fidel García , Orlando Maeso , Fernando Medina, "Influence of the properties of polypropylene fibres on the fracture behavior of low-, normal- and high-strength FRC", Construction and Building Materials, vol. 45, pp. 130-137, 2013.

4. A. Nobili, L. Lanzoni, A.M. Tarantino, "Experimental investigation and monitoring of a polypropylene based fiber reinforced concrete road pavement", Construction and Building Materials, vol. 47, pp. 888-895, 2013.

5. A.A. Ramezanianpour, M. Esmaeili, S.A. Ghahari, M.H. Najafi, "Laboratory study on the effect of polypropylene fiber on durability, and physical and mechanical characteristic of concrete for application in sleepers", Construction and Building Materials, vol. 44, pp. 411-418, 2013.

6. Sydney Furlan Jr, Joao Bento de Hanai, "Behavior of fiber reinforced concrete beams", Cement \& Concrete composites, vol. 19, pp. 359-366, 1997.

7. Ple,O. Le, T.N.H, "Effect of polypropylene fiber-reinforcement on the mechanical behavior of silt clay", Geotextiles and Geomembranes, vol. 32, pp. 111-116, 2012.

8. Machine Hsie, Chijen Tu, P.S. Song, "Mechanical properties of polypropylene hybrid fiber-reinforced concrete", Materials Science and Engineering, vol. 49, pp. 153-157, 2008.

9. Jianping Zhu, Qifang Zhong, Gaige Chen, Dongxu Li, "Effect of particlesize of blast furnace slag on properties of portland cement", Journal on Procedia Engineering, vol. 27, pp. 231-236, 2012.

10. Xinghua Fua, Wenping Hou, Chunxia Yang, Dongxu Li, Xuequan Wu, "Studies on portland cement with large amount of slag", Cement and Concrete Research, vol. 30, pp. 645-649, 2000.

11. Byung Hwan Oh, Dae Gyun Park, Ji Cheol Kim, Young Cheol Choi, "Experimental and theoretical investigation on the postcracking inelastic behavior of synthetic fiber reinforced concrete beams", Cement and Concrete Research, vol. 35, pp. 384-392, 2005.

12. Gonzalo Martinez-Barrera, Fernando Urena-Nunez, Osman Gencel, Witold Brostow, "Mechanical properties of polypropylene-fiber reinforced concrete after gamma irradiation", Composites: Part A, vol. 42, pp. 567-572, 2011.

13. M. Elser, E.K. Tschegg, S.E. Stanzl Tschegg, "Fracture behavior of polypropylene fiber reinforced concrete: Modelling and Computer simulation", Composites Science and Technology, vol. 56, pp. 947-956, 1996. 